\title{
O humor das tiras em quadrinhos na educação para a diversidade sexual
}

\author{
Denise Maria MARGONARI ${ }^{1}$ \\ Amaro Xavier BRAGA JR ${ }^{2}$
}

\section{Introdução}

O Ministério da Educação, por meio de suas subsecretarias especiais, como a de Educação Continuada, Alfabetização e Diversidade, entre outras, têm publicado diversos documentos com orientaçóes para o desenvolvimento da educação para as questóes de Gênero e Diversidade Sexual. Essas questóes contemplam diversas instâncias relacionadas às práticas de constituição do gênero social, da identidade de gênero e suas problematizaçóes sociais e políticas de enfrentamento; a orientação sexual e as questôes relativas à Heteronormatividade e seus problemas decorrentes, tais como o Sexismo e a Homofobia, visando, sobretudo, promover parâmetros para uma pedagogia sobre o gênero e a sexualidade nas escolas.

Tais questôes, polêmicas, enfrentam muitas barreiras para a sua efetivação, como, por exemplo, a política contrária da escola (principalmente quando são de administração religiosa), as ideologias náo assertivas dos pais e professores,

1 UNESP - Universidade Estadual Paulista. Faculdade de Ciências e Letras Departamento de Didática. Araraquara - SP - Brasil. 14800-901 - denisemargonari@ fclar.unesp.br

2 UFAL - Universidade Federal de Alagoas. Instituto de Ciências Sociais. Maceió AL - Brasil. 57072-970 - axbraga@gmail.com 
e a falta de material didático ou orientaçôes pedagógicas aos professores no desenvolvimento dessas açóes.

Os dois primeiros aspectos são macrossociais e dependem de políticas públicas que discutam e reorientem as mentalidades sociais. Já a última, tem uma aplicaçáo microssocial e pode ter um direcionamento, a partir das indicaçóes de uso e descobertas de práticas, as quais os professores tenham acesso.

Nesse sentido, nosso trabalho visa se dirigir a esse último patamar: identificar a aplicabilidade de diversas publicaçóes juvenis, por meio do uso do humor, no desenvolvimento de planos de ação pedagógicos que trabalhem essas questóes na sala de aula e por vias de um veículo que é de fácil acesso e aceitação por parte dos educandos: as histórias em quadrinhos. E, mais enfaticamente, a um tipo de quadrinho que desperta bastante o interesse dos jovens na contemporaneidade, pelo acesso diário em jornais de circulação nacional e regional: as tiras em quadrinhos.

A inter-relação entre quadrinhos e educação tem ocupado muito o tempo de investigadores que demonstraram, por meio de diversas pesquisas, qualitativas e quantitativas, que seu uso é eficaz e benéfico. Dos relatórios educacionais de censo estatístico da Confederação Nacional dos Trabalhadores em Educação CNTE - Brasil (RETRATO DA ESCOLA 2, 2002) às investigaçôes qualitativas de Anselmo (1975), Gottlieb (1996), Calazans (2004), Mattos (2009), Carvalho (2006) e as coletâneas de diversos autores organizadas por Vergueiro e Ramos (2009a; 2009b), Santos Neto e Silva (2011; 2013; 2015) e Modenesi e Braga Jr (2015a; 2015b), de resumo sintetizam, como afirmamos em um momento anterior, que:

[...] o nível baixo de rendimento escolar dos alunos náo está associado ao consumo e leitura de histórias em quadrinhos. Ao contrário, os dados (referem-se à pesquisa do CNTE, supracitada] mostram que os alunos leitores de quadrinhos, sejam oriundos de escolas particulares ou públicas, tendem a ter notas melhores com uma diferença percentual significativa. Os dados também mostram algo interessante: entre os alunos que tiveram baixo rendimento escolar, encontra-se uma associação com a não leitura de quadrinhos. (BRAGA JR, 2013, p. 41-42, grifo nosso).

A grande profusão de trabalhos sobre o tema demonstra claramente as benesses desse tipo de publicaçáo no universo escolar. O que os pesquisadores querem, sobretudo, defender, é que nenhum recurso é melhor do que aquele ao qual o aluno já conhece e consome sem que o "professor, o pai ou o padre" o mandem ler. Além disso, se reconhece que esses veículos de formação exercem importante papel de educação não-formal entre os educandos, conforme orientam os PCNs: "A criança também sofre influências de muitas outras fontes: 
de livros, da escola, de pessoas que não pertencem à sua família e, principalmente, nos dias de hoje, da mídia. Essas fontes atuam de maneira decisiva na formação sexual de crianças, jovens e adultos." (BRASIL, 1997, p.77). Os quadrinhos enquanto mídias são ótimas ferramentas pedagógicas, pois já são materiais que estão sendo consumidos pelos estudantes. São publicaçôes que eles não esperam que estejam envolvidas em suas dinâmicas diárias de estudo, principalmente porque sáo produtos de entretenimento que contem uma cultura, muitas vezes tachada historicamente como "cultura inútil" e, por isso mesmo, despertadora de interesse no alunado. Não há muito esforço ou convencimento na hora de pedir a leitura de uma HQ (ou congênere).

\section{Os quadrinhos e seus congêneres}

As histórias em quadrinhos, de maneira ampla, podem ser entendidas como um hiper gênero, que envolve uma gama variada de produtos artísticos (pois se manifestam por vias de imagens desenhadas) e midiáticos (pois são publicadas em veículos de comunicação, como jornais, Internet e impressos em geral), que se relacionam, em algum nível, com esferas de entretenimento e diversão. Além disso, são objetos sociais (pois possuem uma materialidade) e circulam no meio social como itens de consumo comercial, colecionáveis e de troca. É, sobretudo, a sua materialidade, o que define a sua existência. Não se trata apenas de uma linguagem, de um meio de fazer algo, mas algo concreto que é amparado pelas regras culturais e pelo consumo. Assim sendo, é correto entender as histórias em quadrinhos como "objetos artístico-midiáticos de entretenimento" (BRAGA JR, 2015b).

O que chamamos de quadrinhos (enquanto hiper gênero) são desenhos que, às vezes, podem apresentar parâmetros estéticos particulares, que terminam por nomeá-los de formas diferentes: Caricaturas, Charges, Cartuns, Tiras em Quadrinhos, Revistas de Histórias em Quadrinhos (ou Gibis), Fanzines e Fotonovelas ${ }^{3}$.

A trajetória histórica dessas publicações manteve uma relação muito próxima dos quadrinhos com o humor. As caricaturas, as charges e os cartuns surgiram dessa interface, ou seja, fazer humor e escracho por meio dos desenhos. Esse humor sempre foi baseado em estereótipos sociais e visóes de mundo que em um processo de comunicação inter-simbólico manteve-se em constante diálogo com os leitores. Os desenhos (e os desenhistas) captavam valores sociais em torno da aparência dos indivíduos e os reproduziam por meio da ilustração, despertando o riso ou a piada pela simples relação entre a representação mental de algo e sua

3 Para se aprofundar nas características estéticas de cada um desses padrôes estéticos, consultar: Braga Jr (2015a). 
representação visual, normalmente, exagerada ou posta em ridículo. Nos Estados Unidos, por exemplo, a origem e a definição do termo para tiras em quadrinhos (comic strips) possuem vínculos diretos com a comicidade e o humor.

Antes que adentremos na relação entre o humor, os quadrinhos e a educação sexual, precisamos de um breve esclarecimento quanto a essência do que é o humor e suas implicaçóes.

\section{O humor e suas origens}

De acordo com a definição apresentada pela Enciclopédia Britânica (HUMOR, 2015), a palavra humor é etmologicamente derivada do latim "umor" e significa "líquido" ou "fluído". Segundo a teoria fisiológica ocidental, que permaneceu durante toda a Idade Média e o período da Renascença, o corpo humano era regido por quatro tipos diferentes de humores: o sangue, a fleuma, a bile amarela e a bile negra. As diversas combinaçóes desses quatro elementos determinavam o temperamento, as complexidades, as disposiçóes e as qualidades físicas e mentais das pessoas.

Assim, os indivíduos considerados "ideais" eram aqueles que possuíam uma mistura equilibrada dos quatro fluídos, pois a predominância de apenas um determinaria o homem sanguíneo, o fleumático (calmo), o colérico ou o melancólico. E, de alguma forma, por extensão da teoria, a visão do humor até o século XVI ficou associada a um desequilíbrio de temperamento, a uma condição mental não balanceada, a um estado ou capricho, tolice ou vício irracional.

Neste estudo, dentre as várias acepçóes modernas sobre o tema que foram sendo observadas ao longo da pesquisa (MARGONARI, 2001, 2006), adotamos as definições de humor que aparecem no Dicionário da Oxford (HUMOR, 1995, p. 582-583, tradução nossa) para aprendizes da Língua Inglesa em níveis avançados: 1) "a qualidade de ser divertido ou cômico", 2) "a habilidade de apreciar coisas, situaçóes ou pessoas que são cômicas; a habilidade de ser divertido" e 3) "um estado mental de uma pessoa; um estado".

Já no que concerne às definiçôes do cômico, do riso e do risível, foram utilizadas aquelas propostas por Alberti (1999), estudiosa acerca desses assuntos na história do pensamento ocidental e que aborda o riso como um "conceito ao mesmo tempo filosófico e histórico" e o cômico e o risível como "o objeto do riso" ou "aquilo de que se ri". Entretanto, a autora afirma que as definiçóes terminológicas constituem-se em um verdadeiro obstáculo para se discutir o tema, pois:

4 No original: 1) "the quality of being amusing or comic", 2) "the ability to appreciate things, situations or people that are comic; the ability to be amused" e 3) "a person's state of mind; a mood". (HUMOR, 1995, p.582-583). 
[...] São muitas as categorias ligadas ao nosso objeto de estudo: humor, ironia, comédia, piada, dito espirituoso, brincadeira, sátira, grotesco, gozação, ridículo, nonsense, farsa, humor negro, palhaçada, jogo de palavras ou simplesmente jogo. (ALBERTI, 1999, p. 25).

Nesse sentido, Alberti ressalta a importância de náo se deter nas diferenças terminológicas, pois elas não são expressamente destacadas pelos autores e coincidem ou variam dentre esses estudiosos.

Conforme foi observado, o humor, o cômico, o riso e o risível vêm sendo preocupaçôes permanentes do homem. Segundo Schmitz (1996) e Morreall (1997), humor e riso são componentes básicos da existência humana e estão entre as mais antigas e mais poderosas manifestações sociais que os seres humanos possuem, pois desde os filósofos pré-socráticos já é possível encontrar evidências de estudos dessa natureza.

De acordo com Alberti (1999), o diálogo de Platáo Filebo parece ser o primeiro estudo sistemático sobre a natureza do riso, que começa com uma discussão sobre o prazer, da qual participam Sócrates e o próprio Filebo. Segundo Platão, existem os prazeres verdadeiros e os prazeres falsos. Os primeiros são puros e precisos, enquanto os segundos são sempre afecçóes mistas, em que dor e prazer se misturam. Essas afecçóes mistas se dividem em três categorias: corporais, semi-corporais e semi-espirituais e puramente espirituais. É no contexto dessas últimas que se dá a discussão sobre o riso - "[...] o estado de alma em que nos colocam as comédias [...], que é também uma mistura de dor e prazer." (PLATÃO, 1973, p. 48). Para ele, a comédia - que a princípio só se constituiria de prazer - mistura-se, na realidade, com a dor.

A questão do risível é duplamente definida logo em seguida como um desconhecimento de si mesmo e como uma fraqueza. Aqueles que não se conhecem são vítimas da ilusão em relação a si mesmos e, portanto, se tornam fracos porque se imaginam mais sábios, mais ricos, mais belos ou mais virtuosos do que realmente são.

Durante o diálogo com Filebo, Sócrates também reflete sobre aquele que ri quando trata da definição da inveja, afecção mista puramente espiritual. Quem ri dos males de seus amigos mistura o riso à inveja, o prazer à dor, "[...] pois concordamos há muito que a inveja é uma dor da alma e que o riso é um prazer, e ambos coexistem nessas ocasiōes." (PLATÃO, 1973, p. 49).

Aristóteles segue a mesma linha de Platão, ressaltando o caráter moral do riso. Entretanto, sua definição de cômico corresponde a uma deformidade que náo implica dor nem destruição. Segundo Alberti (1999), talvez seja dele a influência mais importante na história do pensamento sobre o riso, pois essa definição, que se encontra na Poética, estabelece-se como uma característica do cômico já na Antiguidade e atravessa os séculos seguintes. 
A concepção sobre o cômico corresponde a passagens dispersas de sua obra Poética, pois o livro II, que trataria especialmente do assunto, se perdeu. A comédia é citada entre as artes que representam as açóes humanas baixas, ou seja, as personagens são representadas em açóes piores:

A comédia é, como já dissemos, imitação de maus costumes, não contudo de toda sorte de vícios, mas só daquela parte do ignominioso que é o ridículo. $\mathrm{O}$ ridículo reside num defeito e numa tara que não apresentam caráter doloroso ou corruptor. Tal é, por exemplo, o caso da máscara cômica feia e disforme, que náo é causa de sofrimento. (ARISTÓTELES, 1964, p. 269.).

Para Aristóteles, o cômico é uma deformidade moral ou física que, sendo inofensivo e insignificante, não causa dor nem destruição, ao contrário da tragédia, que expressa o terror e a piedade por meio da representação de personagens melhores em ações humanas nobres e verossímeis. A comédia é o não-trágico, suas personagens são inventadas e seus nomes escolhidos ao acaso, ao passo que os poetas trágicos "[...] recorrem a nomes de personagens que existiram, pela razão de que o possível inspira confiança." (ARISTÓTELES, 1964, p.279).

Convém, ainda, destacar que um dos traços característicos da expressão cômica é o emprego de metáforas que, segundo a concepção aristotélica é desmedida e fora de propósito, causando o efeito cômico. Por último, cabe apresentar alguns trechos de sua obra Retórica, que no livro primeiro apresenta o riso e o risível entre as "coisas agradáveis" (ARISTÓTELES, 1964, p. 77): "Como são agradáveis o jogo, o riso e toda a espécie de folga, necessariamente o deve ser tudo o que provoca o riso: pessoas, ditos, atos [...]". Segundo esse pensador, as "coisas agradáveis" estáo relacionadas a tudo que produz prazer, como o habitual, o natural e todo o desejo inato. No que diz respeito ao jogo e à festa, Aristóteles caracteriza o riso e o risível como circunstâncias propícias à calma e à amizade, em que haveria, enfim, ausência de sofrimento.

O livro terceiro da Retórica também contém referências ao riso. Uma delas, localizada na parte consagrada ao estilo, refere-se à troca de letras em uma palavra e a troca de palavras em um verso como recursos cômicos. Aristóteles ressalta a necessidade de se manter evidentes os dois sentidos da palavra, pois, se o orador não consegue expressá-los ao mesmo tempo, ou se ouvinte não conhece a ambos, o jogo de palavras fica sem efeito.

Outra reflexão que merece destaque é sobre o riso como fator surpresa. Para ele, a palavra modificada pela troca de letra produz um efeito diferente do esperado, surpreendendo o espectador e chamando a atenção do ouvinte. Nesse aspecto, o riso e o risível são de grandes utilidades para o orador, adquirindo funções de destaque no discurso oratório. 
Segundo Alberti (1999), que tem como base os estudos de Fuhrmann ${ }^{5}$, o texto pós-aristotélico Tractatus Coislinianus é um conjunto de fragmentos anônimos reunidos sob o título Comicorum Graecorum Fragmenta, composto por textos da antiguidade tardia e bizantinos, em que aparecem definiçóes do cômico semelhantes às de Aristóteles, como, por exemplo, a classificação de suas origens em dois tipos: as expressóes da língua (lexis) e os eventos e as coisas (pragmata), ou seja, o cômico nasce do que é dito ou da ação, correspondendo aos discursos e atos de que fala Aristóteles na Retórica.

Para Alberti (1999), as teorias de Cícero e Quintiliano são provavelmente os primeiros tratados sistemáticos sobre o riso e o risível no pensamento ocidental, em que se dedica um capítulo inteiro de suas obras de retórica ao "ridiculum" (aquilo de que se ri). Em seu tratado De oratore, escrito em 55 a.C. e constituído sob a forma de diálogo, Cícero destina um lugar específico ao risível, que deve ser empregado pelo bom orador. A obra de Quintiliano Institutio oratoria, escrita entre os anos 92 e 94 d.C., também apresenta em meios aos doze livros que a compóem, o terceiro, que se dedica ao ensino do risível na arte retórica e que objetiva a formação do orador. Ambos procuraram definir os modos e os objetivos do emprego do riso como um recurso da oratória, contudo, seus trabalhos continuam fortemente inseridos na análise do tema sob a perspectiva ética.

As concepçôes do riso nos textos medievais dizem respeito à definição de "próprio do homem" e que distingue os seres humanos dos animais e de Deus. De acordo com Alberti (1999), que se utiliza dos estudos de Suchomski ${ }^{6}$, ao longo de toda a Idade Média os julgamentos sobre o riso e o risível variaram segundo duas tendências: a que se referia à Bíblia e a que se apoiava em autores da Antiguidade. As diferenças em relação à apreciação do tema variavam, assim, dependendo do autor ser adepto dos dogmas teológicos ou mais familiarizado com o pensamento clássico.

A primeira delas condenava o riso e o risível, tendo por fundamento as provas bíblicas de que Jesus Cristo jamais rira. Segundo Alberti, nos textos dessa vertente analisados por Suchomski, o risível era proibido por fazer parte do discurso superficial e inútil de que o homem deveria prestar contas no Juízo Final. Observa-se, entretanto, que essas proibiçóes eram dificilmente cumpridas, inclusive pelo próprio clero, ressaltando-se uma grande lacuna entre as prescriçóes oficiais da Igreja e a prática.

A segunda tendência é baseada em argumentos de Aristóteles, Cícero, Quintiliano e Sêneca e também tratava da medida e subordinação do riso e do

5 Alberti se baseia nos estudos de Fuhrmann (1973).

6 Alberti se utiliza do estudo de Suchomski (1975). 
risível aos propósitos sérios. Sua tolerância variava de acordo com o grupo no qual a pessoa se incluia, mais admitido entre cristáos leigos e menos entre sacerdotes e monges. Essas recomendaçôes regulamentavam, assim, o discurso oratório e a conduta digna dos homens livres, determinando o espaço conferido ao riso na vida dos bons cristãos.

Analisando a Idade Média e o Renascimento, Bakhtin (1987, p.3), estudioso da cultura popular nesse período a partir da obra de François Rabelais, assinala que as formas e manifestaçóes do riso se opunham "[...] à cultura oficial, ao tom sério, religioso e feudal da época." Para ele, as múltiplas manifestaçóes da cultura popular desse período podem subdividir-se em três grandes categorias: 1) as formas dos ritos e espetáculos (festejos carnavalescos, obras cômicas representadas em praças públicas, etc.); 2) obras cômicas verbais, orais e escritas em latim ou em língua vulgar (paródias) e 3) diversas formas e gêneros do vocabulário familiar e grosseiro (insultos, juramentos, etc).

Segundo o autor, os festejos de carnaval ocupavam, incluindo atos e ritos cômicos relacionados, um lugar muito importante na vida do homem medieval:

Ao contrário da festa oficial, o carnaval era o triunfo de uma espécie de liberação temporária da verdade dominante e do regime vigente, de abolição provisória de todas as relaçôes hierárquicas, privilégios, regras e tabus. Era a autêntica festa do tempo, a do futuro, das alternâncias e renovaçôes. (BAKHTIN, 1987, p. 8).

Nessas festas criava-se uma segunda vida na população, um "mundo ao revés”, em que desapareciam relaçóes hierárquicas, permitindo o estabelecimento de interaçóes novas e verdadeiramente humanas entre os participantes.

Já no que se refere às obras verbais em língua latina e vulgar, Bakhtin afirma que essa literatura, justamente porque estava repleta dessa concepção carnavalesca de mundo, era festiva e recreativa, repercutindo, até mesmo, dentro dos muros dos mosteiros, de forma que os sábios passavam a escrever tratados cômicos em suas celas. Assim, o riso fazia parte de diversas atividades e manifestaçóes do cotidiano medieval, ou seja, um mundo menor e "não-oficial", que se opunha à visão "oficial" e ao tom de seriedade correspondentes às normas da Igreja e do Estado.

De acordo com Bakhtin, o século XVI foi marcado pelo apogeu da história do riso, que culminou com a obra de Rabelais, em que o tema teve um profundo valor de concepção do mundo. Contudo, no século seguinte, o autor afirma que o riso perdeu seu "colorido histórico", pois o novo regime governamental a monarquia absolutista - estava impregnado de seriedade e autoritarismo, domesticando o risível e banindo-o em função da moral e dos bons costumes para o terreno do ridículo, ou seja, do erro, do vício e do desvio. 
Alberti (1999) aponta que esse julgamento negativo não era um fenômeno novo, pois a oposição riso versus pensamento sério acompanha e marca toda a história do riso e do risível, observando-se sua presença mais acentuada até a teoria de Hobbes (1651 e 1658), que via no riso um estado essencialmente afetivo e o explicava como uma eclosão súbita do sentimento de superioridade.

Segundo Neves (1974), em ensaio dedicado ao estudo da ideologia da seriedade a partir de uma perspectiva antropológica, a dificuldade de tratamento do riso, assim como a existência, por um longo período, de poucas análises científicas relacionadas ao assunto, evidenciam o abandono a que o mesmo era relegado. Para esse autor, as causas de tal abandono tinham como fundamento os aspectos históricos acima levantados, que culminaram na construção de uma ideologia da seriedade e que foi responsável pela imposição de um repertório nobre e sisudo, não apenas ao humor, mas, também, a uma série de temas considerados relevantes e pertinentes que deveriam ser honrados por estudos científicos.

Contudo, no decorrer da história do pensamento ocidental, o julgamento ético negativo e preconceituoso foi se atenuando e começou a ser lentamente modificado ao longo dos séculos com o auxílio de estudiosos das mais diferentes áreas do conhecimento.

Segundo Alberti, que se utiliza dos estudos de Schalk e Tave ${ }^{7}$ a partir da segunda metade do século XVIII, com as crescentes preocupaçóes acerca do ridículo, bem como com a introdução das concepçóes sobre o riso benevolente, houve uma ruptura em relaçáo à censura sobre o objeto cômico enquanto deformidade e desvio.

Entretanto, esse rompimento, que também coincide com o final do Antigo Regime na França, bem como com as obras de Diderot e Rousseau, não é linear, muito menos obedece a uma rígida precisão cronológica, pois, de acordo com Alberti, essa cisão não significa um total abandono do pensamento negativo que vem acompanhando o riso. Para a autora, o que ocorre é uma mudança de perspectiva sobre o modo de pensar o tema, de forma que o risível começa a ser vinculado ao domínio da razão e do entendimento.

No século XX, observa-se que a questão da condenação ética do riso perdeu a força que vinha mantendo desde as teorias da Antiguidade, passando a receber contribuiçóes, como os trabalhos de Freud, na área da psicanálise, que em 1905 escreveu especificamente sobre Os chistes e sua relação com o inconsciente; e o estudo de Huizinga Homo Ludens, de 1938, que revelou a importância da análise de atividades não-sérias no campo das ciências humanas.

7 Alberti se baseia em Schalk (1977) e Tave (1960). 
Já em relação ao famoso trabalho de Bergson (1983) - O riso: ensaio sobre a significação do cômico - um dos estudos mais conhecidos e citados nas pesquisas contemporâneas sobre o humor, autoras como Gil (1991) e Alberti (1999), afirmam que ele ainda apresenta fortes traços morais ao definir o cômico como uma manifestação negativa que o riso tinha por tarefa corrigir.

Assim, na medida em que as pesquisas foram evoluindo, a importância do humor foi se evidenciando, bem como as vantagens de sua aplicação em diversas áreas do conhecimento.

De acordo com Gil (1991), pesquisadora que desenvolveu uma proposta para o estudo de piadas, a década de setenta parece ser o auge das pesquisas na área humorística, principalmente aquelas relacionadas à psicologia. Segundo a autora, nesse período também começaram a se organizar os primeiros congressos nacionais e internacionais sobre o humor nos Estados Unidos, demonstrando o alto grau de interesse a que chegou esse tipo de investigaçáo naquele país. Até mesmo nos dias atuais, esses congressos continuam ocorrendo, abordando o humor em vários contextos específicos, como, por exemplo, na área dos negócios, na educação, nas interações sociais, na Literatura, no Direito, além de suas aplicaçôes terapêuticas e psicológicas.

Entretanto, no contex to educacional ainda existem poucos trabalhos e aplicaçôes práticas relacionados ao seu uso pedagógico. Para alguns estudiosos acerca do humor, entre eles Neves (1974), Maurice (1988), Chiaro (1996) e Morreall (1997), esse fato está arraigado nas suas próprias origens, que desde a Antiguidade Clássica é encarado de uma perspectiva ética negativa, moralizadora e transgressora.

Somando-se a esses pontos de vista depreciativos, Maurice (1988) aponta que a rara presença do lúdico na educação também se explica pelo fato de a aprendizagem ser um processo fundamental na existência de quase todas as sociedades e, devido a sua importância, muitas pessoas a consideram como uma atividade que deve ser encarada somente de uma maneira rigorosa e sisuda, pois a emoção não deve "desviar" o processamento de informaçôes.

A partir dessa breve imersão sobre os estudos acerca do humor, e com o objetivo de ressignificar a visão negativa que percorreu a sua relação com a educação, seguimos explicitando os casos em que o tema das tiras produzidas no Brasil se apropriaram da temática da diversidade sexual.

\section{Tiras em quadrinhos com foco na diversidade sexual}

O Brasil tem uma trajetória expressiva na produção de tiras em quadrinhos, em sua maioria, de tendência cômica. Muitas delas circularam pela temática da sexualidade e das identidades sexuais, apresentando questôes diversas, que são possíveis de discussão na sala de aula. 
A seguir, listamos um apanhado dessas publicações e de seu perfil, visando munir o professor de material que possa vir a ser utilizado como recurso didático no Ensino Fundamental 2 e Ensino Médio.

Esses usos, como orientam os PCNs, devem ser transversais, por isso, podem ser incluídos nas aulas de Língua Portuguesa (a partir da análise das construçóes textuais ou nas de gênero textual), nas aulas de Língua Estrangeira, em processos de tradução e compreensão de diálogos, por exemplo, assim como é possível inseri-las nas aulas de Sociologia, História e Artes.

Segundo Magalhães (2014), em 1976, os Fradins de Henfil já apresentavam temáticas homossexuais de maneira cômica e escrachante. Na década de 1970, em João Pessoa, é publicada a tira "Maria", retratando uma simpática lésbica em suas reflexôes diárias sobre o cotidiano. Outra personagem lésbica que faz sucesso e que chegou a ser publicada nesse estado pela editora Marca de Fantasia, é "Katita", de Anita Prado e Ronaldo Mendes. Também na Paraíba, surgem as tirinhas do "Adrian", de Emir Ribeiro, retratando de forma satírica as dificuldades de uma pessoa hermafrodita.

Figura 1 - Tirinha de "Maria", de Henrique Magalhães.
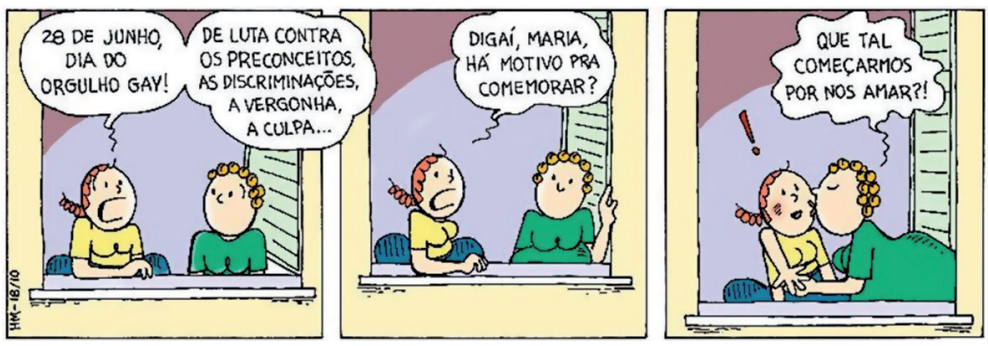

Fonte: Magalhães (2010).

Figura 2 - Tirinha de "Katita", de Anita Prado e Ronaldo Mendes.
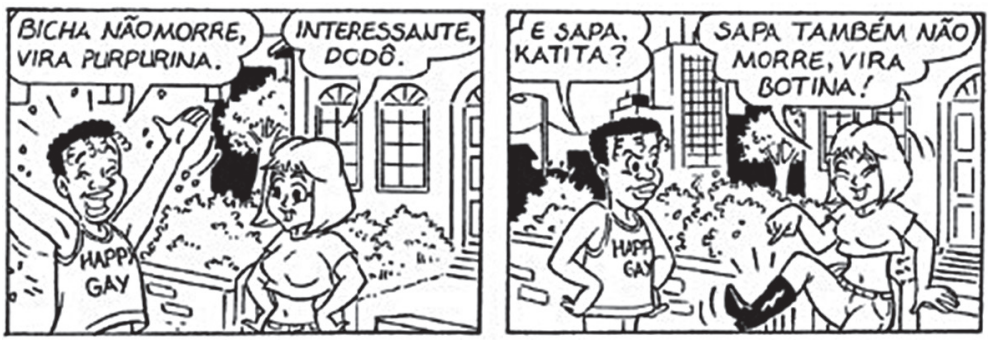

Fonte: Prado e Mendes (2015). 
A grande leva de personagens e enredos segue nos anos $80 \mathrm{com}$ diversos cartunistas brasileiros:

A partir dos anos 1980 surgiu com força na imprensa diária e nas revistas em quadrinhos personagens urbanos e malditos no traço de Angeli, Laerte e Adáo Iturrusgarai. Angeli apresentaria em 1983 o personagem Nanico, companheiro de luta de certa esquerda revolucionária, que encarava os novos tempos de abertura política assumindo sua homossexualidade até então reprimida. Em 1985 Adão faria uma hilária sátira com os cowboys gays Rocky e Hudson, desmontando o clichê de masculinidade dos filmes de faroeste. Laerte, mais tarde, faria seu personagem Hugo assumir o travestismo como expressáo de suas fantasias sexuais. (MAGALHÃES, 2014, p. 145).

Figura 3 - "Nanico", de Angeli. Um homossexual sem comportamento afeminado, mas com apelo de humor
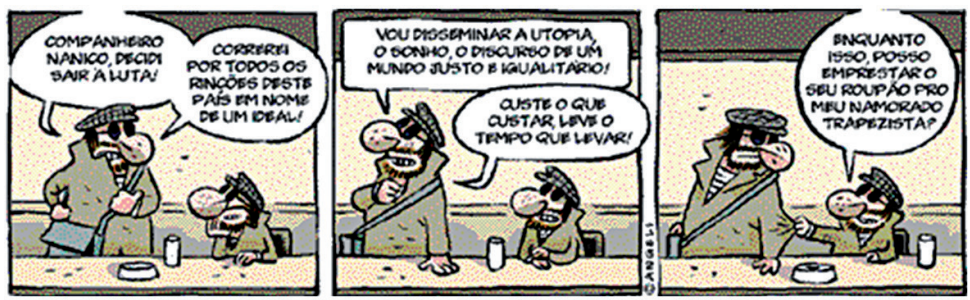

Fonte: Angeli (2015).

Figura 4 - "Rocky e Hudson", de Adão Iturrusgarai, retratando dois gays gaúchos com muita sátira.
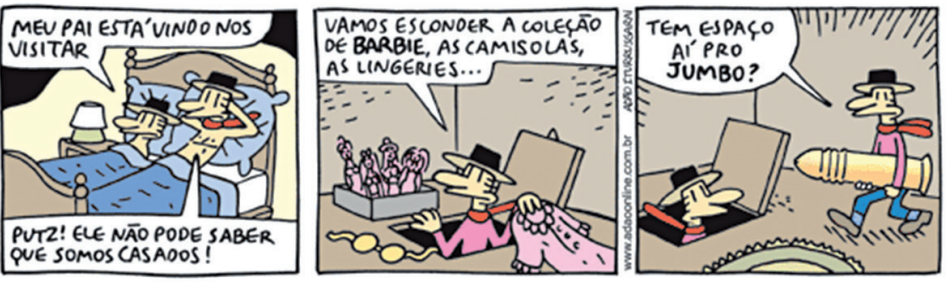

Fonte: Adão Iturrusgarai (2015). 
Figura 5 - Tirinha de Laerte retratando a Muriel e as vicissitudes enfrentadas por um transgênero.
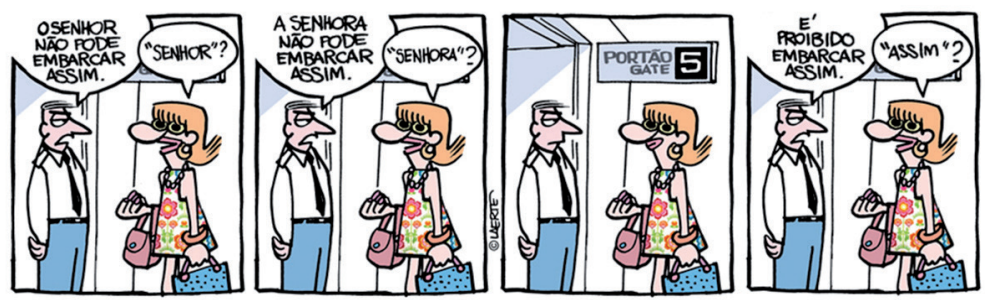

Fonte: Laerte (2015).

Nos anos 90, ganha o reforço político e ideológico de Laerte, que assume uma identidade de crossdressing e transforma seus quadrinhos em objeto de defesa dos transgêneros, nos quais os personagens da tira são um tipo de papel autobiográfico, com forte apelo político.

Além dessas produçôes de circulação nacional, muitas outras foram (e continuam) sendo produzidas com circulação regional ou pela Internet, de artistas que retratam comicamente as vicissitudes enfrentadas pelos transgêneros, ou com discussão relevante sobre o tema. Em 2002, Marcio Baraldi publicou um álbum de tiras com personagens homossexuais, cujas piadas e brincadeiras retratadas tratavam o tema de maneira comprometida.

É também o caso da tirinha "Apolônia vai à luta" de Antônio Aristides; "Ber, the bear", de Rafael Lopes, que retrata a vida dos "Ursos", como são chamados os homens gays peludos, e "Torta de Climão", de Kris Barz, que faz uma webtira com temática gay, distribuída por meio de uma página no Facebook.

Figura 6 - Tirinha de "Apolônio vai à luta", de Antônio Aristides, Marcelo Silva e Leko Magri.
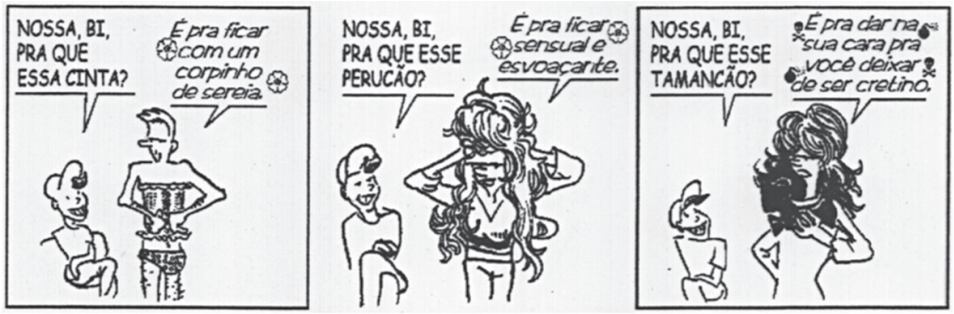

Fonte: Aristides, Silva e Magri (2015). 
Figura 7 - Ber, the Bear, de Rafal Lopes.

Um humor sobre os gays peludos e gordinhos.

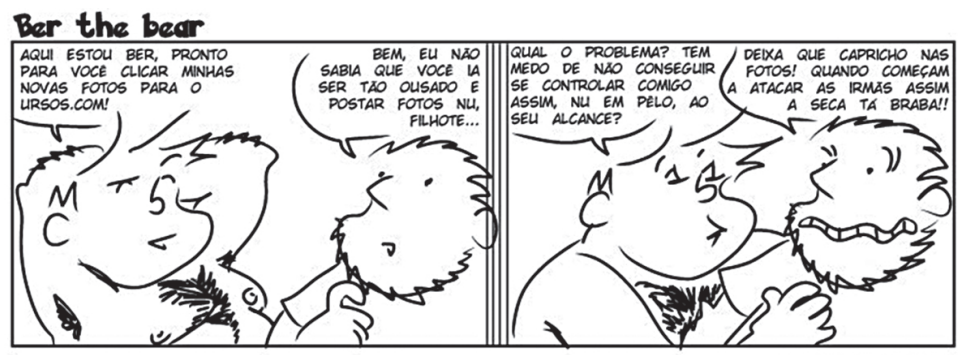

copyright por R. Lopes

Fonte: Lopes (2015).

Figura 8 - Torta de Climão, de Kris Barz, retratando com humor a vida de homens gays.

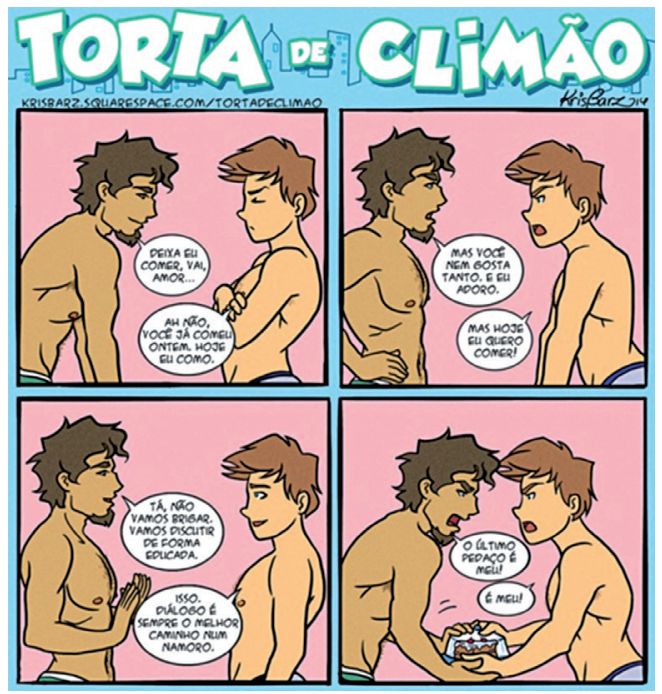

Fonte: Kris Barz (2015).

\section{Considerações finais}

$\mathrm{O}$ riso do travestismo masculino ou feminino, às vezes, pode ser confundido com falta de respeito ou desaprovação. É o ridículo medieval do humor que retorna ao imaginário social. Entretanto, o mesmo riso, no caso dos quadrinhos e no desenho de humor, em geral, pode ser um veículo para a naturalizaçáo da representação. Acostumar-se ao fato e torná-lo natural e frequente é um meio 
para entender que a caracterização fora dos padrôes heteronormativos é possível e não mais estranha (ao passo que se naturalize). Lembremo-nos que muitos dos travestis seguem carreira de comediantes ou animadores, assumindo novos papeis de Drag Queens (ou Drag Kings, em sua versão feminina). É, pelo exagero e pela quebra com o padrão de vestimenta (homens com roupas de mulheres ou o contrário), que o humor se constrói, em princípio.

As tiras em quadrinhos já estão disponíveis e, muitas vezes, já estão sendo lidas pelos educandos. Cabe ao professor aproximar essas duas situaçôes: a necessidade de se discutir as temáticas da educação para a diversidade e o papel do humor na construçáo de um saber direcionado e transversal, que possibilite uma visão crítica e tolerante da sociedade.

Os artistas já fizeram sua parte: produziram discursos imagéticos apoiados no humor, retratando tudo aquilo que precisa ser dito e esclarecido. Fica ao professor se conscientizar da existência desse material e usufruí-lo em beneficio da sociedade. 


\section{REFERÊNCIAS}

ADÃO ITURRUSGARAI. Rocky e Hudson. Disponível em: <http://adao.blog.uol.com.br/ images/ROCKY-E-HUDSON-2484.gif>. Acesso em: 10 jan. 2015.

ALBERTI, V. O riso e o risível: na história do pensamento. Rio de Janeiro: Jorge Zahar, 1999.

ANGELI. Nanico. Disponível em: <http://2.bp.blogspot.com/_znXjK1c1YKE/ TNPEsHuNAmI/AAAAAAAAlHw/OuuPVd5KQFA/s640/ange04042006.gif>. Acesso em: 10 jan. 2015.

ANSELMO, Z. A. Histórias em quadrinhos. São Paulo: Vozes, 1975.

ARISTIDES, A.; SILVA, M.; MAGRI, L. Apolônio vai à luta. [2015]. Disponibilizado pelo autor.

ARISTÓTELES. Arte retórica e arte poética. Tradução de Antônio Pinto de Carvalho. São Paulo: Difusão Européia, 1964.

BAKHTIN, M. A cultura popular na Idade Média e no Renascimento: o contexto de François Rabelais. Tradução de Yara Frateschi Vieira. São Paulo: Hucitec, 1987.

BARZ, K. Torta de Climão. Disponível em: <http://static1.squarespace.com/static/533a21d be4b07771f2d38c53/54029e92e4b0c1de7262e1e4/54358eebe4b0c23fab6c3f95/14128115 55381/come-ou-deixa-comer.jpg?format=750w>. Acesso em: 10 jan. 2015.

BERGSON, H. O riso: ensaio sobre a significação do cômico. Tradução de Nathanael C. Caixeiro. 2. ed. Rio de Janeiro: Zahar, 1983.

BRAGA JR, A. X. As linguagens dos quadrinhos enquanto recurso didático nas aulas de sociologia. In: BRAGA JR, A. X.; MODENESI, T. Quadrinhos \& educação Maceió: Edufal, 2015a. p.07-28. (Procedimentos Didáticos ; v.2).

Por uma sociologia da imagem desenhada: reprodução, estereótipo e actância nos quadrinhos de super-heróis da Marvel Comics. 2015. Tese (Doutorado em Sociologia) Universidade Federal de Pernambuco, Recife, 2015 b.

Quadrinhos independentes: usando imagens para contar muito mais que história. In: MODENESI, T. (Org.). Quadrinhos e educaçáo em 5 pontos de vista. Recife: Ed. da UFPE, 2013. p. 39-62.

BRASIL. Ministério da Cultura. Secretaria de Educação Fundamental. Orientação sexual. Brasília, 1997. Disponível em: <http://portal.mec.gov.br/seb/arquivos/pdf/livro102.pdf>. Acesso em: 25 ago. 2015.

CALAZANS, F. História em quadrinhos na escola. São Paulo: Paulinas, 2004.

CARVALHO, D. A Educação está no Gibi. São Paulo: Papirus, 2006.

CHIARO, D. The Language of Jokes: analysing verbal play. New York: Routledge, 1996.

FREUD, S. Os chistes e sua relaçáo com o inconsciente. Tradução de Jayme Salomão. v. VIII. Rio de Janeiro: Imago, 1996. 
FUHRMANN, M. Einführung in die Antike Dichtungstheorie. Darmstadt: Wisenschaftliche Buchgesellschaft, 1973.

GIL, C. M. C. A linguagem da surpresa: uma proposta para o estudo da piada. 1991. 220 f. Dissertação (Mestrado) - Faculdade de Filosofia, Letras e Ciências Humanas, Universidade de São Paulo, São Paulo.

GOTTLIEB, L. Mafalda vai à escola: a comunicação dialógica de Buber e Moreno n Educação, nas tiras de Quino. São Paulo: Iglu/CCA/ECA/USP, 1996.

HUIZINGA, J. Homo Ludens: o jogo como elemento de cultura. Tradução de João de Paulo Monteiro. São Paulo: EDUSP, 1971.

HUMOR. In: ENCYCLOPAEDIA BRITANNICA. Disponível em: <http://www. britannica.com/topic/humor-ancient-physiology>. Acesso em: 15 dez. 2015.

HUMOR. In: OXFORD ADVANCED LEARNERS. 5.ed. Oxford: Oxford University Press, 1995. p. 582-583.

LAERTE. Muriel. Disponível em: <http://cdn.wp.clicrbs.com.br/plural/files/2014/12/ laerte_3_tirinha.jpg >. Acesso em: 10 jan. 2015.

LOPES, R. Ber, the bear. Disponível em: <http://i1.wp.com/www.bearnerd.com.br/wpcontent/uploads/2010/12/tira-2010-16.jpg>. Acesso em: 10 jan. 2015.

MAGALHÁES, H. A homossexualidade nos quadrinhos brasileiros. In: BRAGA JR, A. X. (Org.). Questóes de sexualidade nas histórias em quadrinhos. Maceió: EDUFAL, 2014. p.241-253.

Rendez-vous: com Maria e Pombinha. Marmota, Paraíba, n.10, jun. 2010. Disponível em: <https://namarmota.files.wordpress.com/2011/03/rendez-vous-18-2010web1.jpg >. Acesso em: 10 jan. 2015.

MARGONARI, D. M. A competência humorística e a criatividade no processo de formação de professores de Língua Inglesa. 2006. 213f. Tese (Doutorado em Educaçáo Escolar) - Faculdade de Ciências e Letras, Universidade Estadual Paulista, Araraquara, 2006.

O papel do humor no processo de ensino-aprendizagem de Língua Inglesa. 2001. 181f. Dissertação (Mestrado em Educação Escolar) - Faculdade de Ciências e Letras, Universidade Estadual Paulista, Araraquara, 2001.

MATTOS, G. de. Desmontando os quadrinhos: história em quadrinhos, educação e regionalidade. Mato Grosso: Ed. da UFMT, 2009.

MAURICE, K. Laugh while learning another language: techniques that are functional and funny. English Teaching Forum, [S.1.], p.20-24, Apr. 1988.

MODENESI, T.; BRAGA JR, A. X. (Org.). Quadrinhos \& educaçáo: relatos de experiência e análises de publicação. Jaboatão dos Guararapes: Faculdade dos Guararapes, 2015a. v.1.

Quadrinhos \& educaçáo: procedimentos didáticos. Jaboatão dos Guararapes: Faculdade dos Guararapes, 2015b. v.2.

MORREALL, J. Humor works. Massachusetts: HRD, 1997. 
NEVES, L. F. B. A ideologia da seriedade e o paradoxo do coringa. Revista de Cultura Vozes, Rio de Janeiro, ano 68, n. 1, p. 35-40, jan/fev. 1974.

PLATÃO. Filebo. In: Diálogos. Belém: Universidade Federal do Pará, 1973. p.4849. v.8.

PRADO, A.; MENDES, R. Katita. Disponível em: <http://oglobo.globo.com/blogs/ arquivos_upload/2007/05/55_2420-alt-katita2.jpg>. Acesso em: 10 jan. 2015.

RETRATO da escola 2: a realidade sem retoques da educação no Brasil. Confederação Nacional dos Trabalhadores em Educação. CNTE, maio 2002. Disponível em: <http://www. cnte.org.br/images/pdf/pesquisa_retrato_da_escola_2.pdf>. Acesso em: 29 jun. 2008.

SANTOS NETO, E. dos; SILVA, M. R. P. da. (Org.). História em quadrinhos e práticas educativas: os gibis estão na escola, e agora? Sáo Paulo: Criativo, 2015.

História em quadrinhos e práticas educativas: o trabalho como universos ficcionais e fanzines. São Paulo: Criativo, 2013.

. História em quadrinhos \& educaçáo: formação e prática docente. São Bernardo do Campo: UMESP, 2011.

SCHMITZ, J. R. Humor: é possível traduzi-lo e ensinar a traduzi-lo? Tradterm, São Paulo, v.3, p.87-97, 1996.

SCHALK, F. Das Lächerliche in der französischen Aufklärung. In: Studien zur französischen Aufklärung. 2.ed.rev. ampl. Frankfurt: Vittorio Klostermann, 1977. p.164205.

SUCHOMSKI, J. 'Delectatio' und 'Utilitas': Ein Beitrag zum Verständnis mittelalterlicher komischer Literatur. Bern: Munique, 1975.

TAVE, S. M. The amiable humorist: A study in the comic theory and criticism of the 18th and early 19th centuries. Chicago: University of Chicago Press, 1960.

VERGUEIRO, W., RAMOS, P. (Org.). Muito além dos quadrinhos: reflexôes sobre a 9a arte. Sáo Paulo: Devir, 2009a.

Quadrinhos na educaçáo: da rejeição à prática. São Paulo: Contexto, 2009b. 


\section{Resumo}

O humor das tiras em quadrinhos na educação para a diversidade sexual

O trabalho busca analisar o papel do humor nas tiras em quadrinhos brasileiras, cuja temática está relacionada à diversidade sexual, com o objetivo de apresentar possibilidades de análises do tema, como conteúdo transversal, na educação para a diversidade sexual. Constitui-se de um levantamento de publicaçóes brasileiras, com a descrição de suas práticas. Discorre sobre a concepçáo do humor historicamente e de seus vínculos com as ideias de deformidade moral e a condenaçáo ética do riso. Propondo uma perspectiva de ressignificação dessa concepçáo de riso sobre o tema da diversidade, como objeto de resistência dos autores nas defesas de seus ideais, incentivamos o uso dos quadrinhos como recurso didático na sala de aula.

Palavras-chave: Quadrinhos. Humor. Educação sexual.

\section{Abstract}

Humor comic strips in the education for sexual diversity

The work analyzes the role of humor in Brazilian comic strips, whose theme is related to sexual diversity, with the aim of presenting possibilities for theme analysis, such as crosscontent, in education for sexual diversity. It consists of a survey of Brazilian publications, with a description of their practices. Discusses the concept of humor historically and its links with moral deformity of ideas and ethical condemnation of laughter. Proposing a redefinition of perspective of this conception of laughter on the subject of diversity, as object of resistence of authors defending their ideals, we encourage the use of comics as a teaching tool in the classroom.

Keywords: Comics. Humor. Sexual education. 
